\title{
OPTICAL-OPTICAL DOUBLE RESONANCE SPECTROSCOPY OF NO2 IN THE 590.1 NM REGION
}

\author{
KAZUHIKO SHIBUYA, TADASI KUSUMOTO and HIDEKAZU NAGAI \\ Department of Chemistry, Tokyo Institute of Technology, Ohokayama, Meguro, \\ Tokyo 152, Japan
}

(Received 24 April 1993)

Optical-optical double resonance (OODR) spectroscopy has been applied to the rotational and vibronic analysis of the thirty nine eigenstates of $\mathrm{NO}_{2}$ existing in the energy region of $16,980-17,124 \mathrm{~cm}^{-1}$ above the ground state. These excited states are concluded to be the mixed states of $\mathrm{NO}_{2}$ generated by spin-orbit and/or orbital-rotation interaction between the $\mathrm{B}_{2}$ and $\mathrm{A}_{1}$ vibronic levels. The mixing mechanism of the excited states is discussed in terms of available information on the visible excited states of $\mathrm{NO}_{2}$.

KEY WORDS: $\mathrm{NO}_{2}$, optical-optical double resonance, spin-orbit interaction

\section{INTRODUCTION}

The visible absorption spectrum of $\mathrm{NO}_{2}$ is extremely complex and far from the analysis by traditional spectroscopic methods. Its complexity is due to the state interaction of vibronic levels locating at $2-3 \mathrm{eV}$ above the ground state. ${ }^{1}$ Even in the supersonic free jet experiments ${ }^{2-6}$ where rotation-induced level mixing is minimized, the structure of the origins of the ${ }^{2} \mathrm{~B}_{2}$ vibronic levels is too irregular to be analyzed by a conventional method based on pattern recognition. The number of identified ${ }^{2} \mathrm{~B}_{2}$ vibronic levels exceeds that of vibrational levels of $\widetilde{\mathrm{A}}^{2} \mathrm{~B}_{2}$ and is nearly equal to that of the high-lying vibrational levels with $b_{2}$ symmetry of $\widetilde{X}^{2} A_{1}$. It is believed that almost all of the $a_{1}$ vibrational levels of $\widetilde{A}^{2} B_{2}$ are vibronically mixed with the high-lying vibrational levels of $\widetilde{\mathrm{X}}^{2} \mathrm{~A}_{1}$ with $\mathrm{b}_{2}$ symmetry and make a number of ${ }^{2} \mathrm{~B}_{2}$ vibronic levels responsible for the visible absorption. Brand et al. ${ }^{7}$ identified the anomalous transitions in the fluorescence spectra measured by the photoexcitation in the $500 \mathrm{~nm}$ region, which was explained by spin-orbit interaction between $\widetilde{\mathrm{A}}^{2} \mathrm{~B}_{2}$ and the high-lying vibrational levels of $\widetilde{X}^{2} \mathrm{~A}_{1}$. Thus, spin-orbit interaction destroys the goodness of rotational quantum numbers, $\mathrm{N}$ and $\mathrm{K}_{\mathrm{a}}$ in the excited state of $\mathrm{NO}_{2}$.

An optical-optical double resonance (OODR) method has been applied to the analysis of the visible absorption spectrum of $\mathrm{NO}_{2}$ and the elucidation of the interaction network of the excited states. ${ }^{8-13}$ First, a single rovibronic level in the excited state is prepared as an intermediate state by the first visible laser $\left(v_{1}\right)$. The second 
visible laser $\left(v_{2}\right)$ excites $\mathrm{NO}_{2}$ in the intermediate state of interest further to the final state of $2^{2} \mathrm{~B}_{2}(0,0,0)$ locating at $4.98 \mathrm{eV}$ above the ground state. The occurrence of the double resonance was monitored by the ultraviolet emission corresponding to the $2^{2} \mathrm{~B}_{2}-\widetilde{\mathrm{X}}^{2} \mathrm{~A}_{1}$ transition. The OODR method offers two major advantages. First, the OODR spectra are simple in rotational structure and easily assigned. The simplification comes from optical selection rules and the state selectivity due to two-photon excitation. Both ${ }^{\text {ev }} \mathrm{A}_{2}-^{\text {ev }} \mathrm{A}_{1}$ and ${ }^{\text {ev }} \mathrm{B}_{1}-{ }^{\text {ev }} \mathrm{B}_{2}$ transitions are optically forbidden under $C_{2 v}$ symmetry. Without any state mixing, only ${ }^{\text {ev }} B_{2}$ is expected to be the intermediate state, because the initial and final states are of ${ }^{\mathrm{ev}} \mathrm{A}_{1}$ and ${ }^{\mathrm{ev}} \mathrm{B}_{2}$ symmetry, respectively. A single rovibronic level can be selected by tuning $v_{1}$ to specific transition energy. Second, the accurate molecular parameters of both the initial and final states are reported ${ }^{14,15}$ and hence one can determine the rotational quantum numbers and vibronic symmetry of the intermediate state independently from the $v_{1}$ - and $v_{2}$-transitions. Since the symmetry of the final state $\left({ }^{\mathrm{ev}} \mathrm{B}_{2}\right)$ is different from that of the initial state $\left({ }^{\mathrm{ev}} \mathrm{A}_{1}\right)$, these types of data have provided information on the state interaction network of $\mathrm{NO}_{2} \cdot{ }^{9-13}$

In this paper, the OODR spectra of $\mathrm{NO}_{2}$ measured in the $590.1 \mathrm{~nm}$ region were analyzed to obtain information on the interaction network in the excitation energy region of $16,980-17,124 \mathrm{~cm}^{-1}$. In many cases, the apparent rotational quantum numbers were assigned to be different depending on the probed transition, $v_{1}$ or $v_{2}$. It is concluded that the intermediate state is a mixed state generated from ${ }^{\mathrm{ev}} \mathrm{B}_{2}$ and ${ }^{\mathrm{cv}} \mathrm{A}_{1}$ through by spin-orbit interaction with the selection rules, $\Delta \mathrm{N}=0, \pm 1$ and $\Delta \mathrm{K}_{\mathrm{a}}= \pm 1$, and/or orbital-rotation interaction with the rules, $\Delta \mathrm{N}=0$ and $\Delta \mathrm{K}_{\mathrm{a}}= \pm 1$. The state interaction network of $\mathrm{NO}_{2}$ is discussed mainly in terms of information based on the OODR experiments.

\section{EXPERIMENTAL}

The output beam of a XeCl excimer laser (Lambda Physik EMG103E MSC) was split into two beams and used to excite simultaneously two dye lasers (Lambda Physik FL-2002E). The first dye laser was used to excite $\mathrm{NO}_{2}$ to a rovibronic level in the visible excited state ( $v_{1}$-transition). The bandwidth of the $v_{1}$-laser was reduced to $0.04 \mathrm{~cm}^{-1}$ by using an intracavity etalon, almost equal to the Doppler width at room temperature. The second dye laser (the bandwidth of $0.3 \mathrm{~cm}^{-1}$ ) was used to excite $\mathrm{NO}_{2}$ in the intermediate state further to the $2^{2} \mathrm{~B}_{2}$ state $\left(v_{2}\right.$-transition). The delay time of about $20 \mathrm{~ns}$ between the two laser pulses was set to avoid the first step absorption by the $v_{2}$-laser. Dyes used were LC-5900 and LC-4200 (Lambda Physik). The wavenumber calibrations of $v_{1}$ and $v_{2}$ were made by measuring the LIF excitation spectrum of iodine (the estimated precision of $0.04 \mathrm{~cm}^{-1}$ ) and the opto-galvanic spectrum of $\mathrm{Ne}$ (the estimated precision of $0.3 \mathrm{~cm}^{-1}$ ), respectively. The UV fluorescence was detected by a solar-blind photomultiplier (Hamamatsu R166) after being passed through a bandpass filter (Corning 7-54). The signals were amplified by a preamplifier (PAR 105, x10) and averaged with a boxcar integrator (PAR 162/165). The $\mathrm{NO}_{2}$ pressure was kept constant at 1.0 Torr throughout the experiments. 


\section{RESULTS}

Figure 1 shows typical two kinds of OODR spectra measured in this OODR experiment. The $v_{2}$-scanned spectrum (a) was measured by fixing $v_{1}$ at $16,939.09 \mathrm{~cm}^{-1}$ and scanning $v_{2}$ over $23,140-23,190 \mathrm{~cm}^{-1}$. Under $\mathrm{C}_{2 \mathrm{~V}}$ symmetry, the $\mathrm{B}_{2}-\mathrm{B}_{2}$ transition is of a perpendicular type with the optical selection rules, $\Delta \mathrm{N}=0, \pm 1$ and $\Delta \mathrm{K}_{\mathrm{a}}=$ \pm 1 . As shown in Figure 1a, the $v_{2}$-scanned OODR spectrum typically consists of six lines, exhibiting the rotational structure of $2^{2} \mathrm{~B}_{2}(0,0,0)$. The terminating rotational level in the $2^{2} \mathrm{~B}_{2}$ state could be easily assigned as indicated in Figure 1a, using the molecular parameters reported for the final state of $2^{2} \mathrm{~B}_{2}(0,0,0) .{ }^{15}$ Taking account of
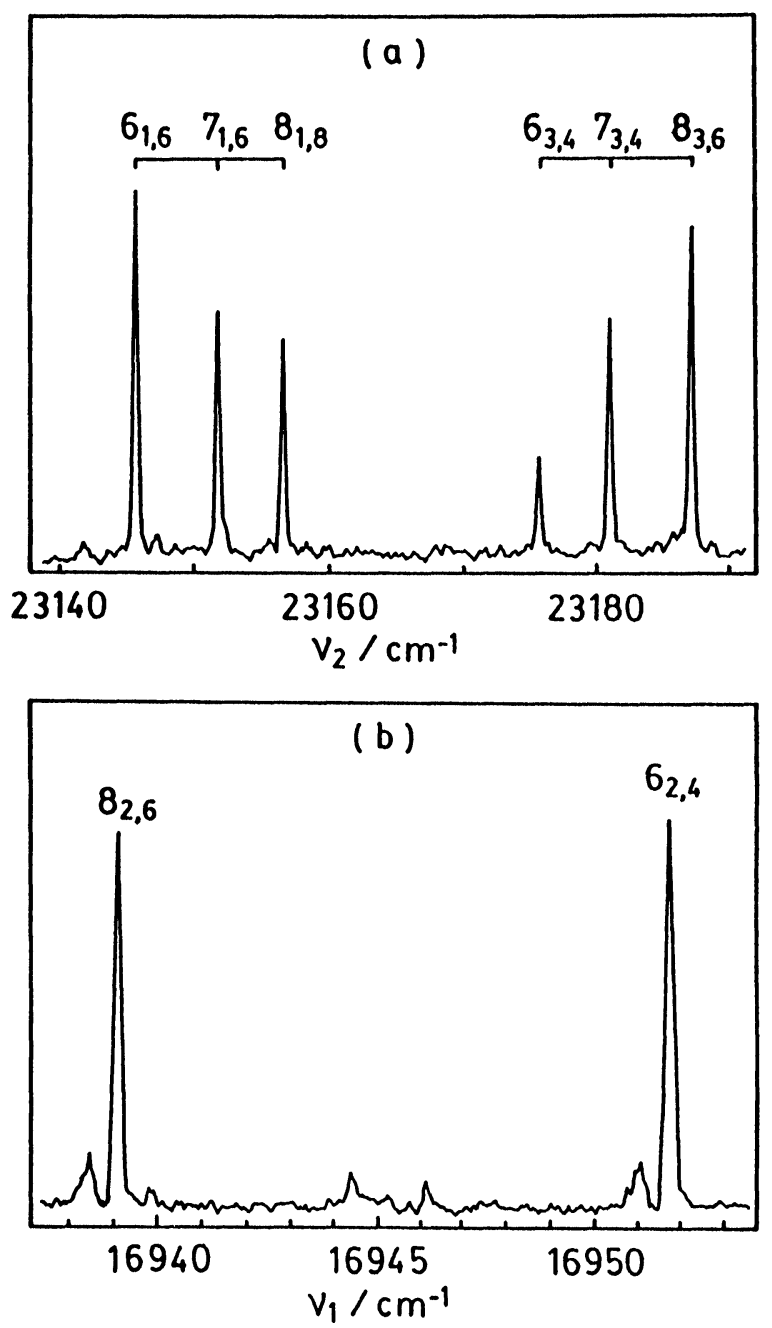

Figure 1 (a) A $v_{2}$-scanned OODR spectrum measured by fixing $v_{1}$ at $16,939.09 \mathrm{~cm}^{-1}$. (b) A $v_{1}$-scanned OODR spectrum measured by fixing $v_{2}$ at $23,145.4 \mathrm{~cm}^{-1}$. 
the assignments and the selection rules on the transition, the rotational quantum number of the intermediate level could be assigned to $7_{2,5}$.

Figure $1 \mathrm{~b}$ shows the $v_{1}$-scanned OODR spectrum obtained by fixing $v_{2}$ at $23,145.4 \mathrm{~cm}^{-1}, \mathrm{PP}_{2}(7)$ in the spectrum shown in Figure 1a. Exactly the same OODR spectrum was obtained when the $v_{2}$-wavenumber was tuned to any of the other five lines measured in Figure 1a. In the $v_{1}$-scanned OODR spectrum, the $v_{2}$-wavenumber was fixed at certain transition energy terminating on a single rovibronic level of $2^{2} B_{2}(0,0,0)$. Then, the OODR spectrum observed corresponds to the excitation spectrum from the ground $\bar{X}^{2} A_{1}$ state to a specified rotational level in the intermediate vibronic state. The $A_{1}-B_{2}$ transition is of a parallel type, with the optical selection rules, $\Delta \mathrm{N}=0, \pm 1$ and $\Delta \mathrm{K}_{\mathrm{a}}=0$. Line strength of ${ }^{\mathrm{Q}} \mathrm{Q}$ branch $\left(\Delta \mathrm{N}=\Delta \mathrm{K}_{\mathrm{a}}=0\right)$ is so weak that most of the ${ }^{\mathrm{q}} \mathrm{Q}$ branches could not be observed in this experiment. As a result, the $v_{1}$-scanned OODR spectrum consists of two lines, ${ }^{9} \mathrm{P}$ and ${ }^{\mathrm{a}} \mathrm{R}$, as shown in Figure $1 \mathrm{~b}$. The originating rotational levels in the $\bar{X}^{2} \mathrm{~A}_{1}$ state responsible for the two lines can be easily assigned as indicated in Figure $1 \mathrm{~b}$, using the molecular parameters reported for the initial state, $\overline{\mathrm{X}}^{2} \mathrm{~A}_{1}(0,0,0) .{ }^{14}$ Thus, the rotational quantum number of the intermediate vibronic state, $\mathrm{N}_{\mathrm{Ka}, \mathrm{Kc}}^{\prime}\left(v_{1}\right)$, was assigned to $7_{2,5}$.

The assignment procedures mentioned above were used to obtain the rotational quantum number of the intermediate state. As a result, the quantum numbers and vibronic symmetry of the intermediate state were determined independently from the $v_{1}$ - and $v_{2}$-scanned spectra. To avoid confusion, the rotational quantum numbers of the intermediate state are denoted by $\mathrm{N}_{\mathrm{Ka}, \mathrm{Kc}}^{\prime}\left(v_{1}\right)$ and $\mathrm{N}_{\mathrm{Ka}, \mathrm{Kc}}^{\prime}\left(v_{2}\right)$ corresponding to the probed $\nu_{1}$ - and $v_{2}$-transitions, respectively. In the case of the intermediate state shown in Figure 1, the numbers of $\mathrm{N}_{\mathrm{Ka}, \mathrm{Kc}}\left(v_{1}\right)$ accord with those of $\mathrm{N}_{\mathrm{Ka}, \mathrm{Kc}}\left(v_{2}\right)$ : $\mathrm{N}_{\mathrm{Ka}, \mathrm{Kc}}^{\prime}\left(v_{1}\right)=\mathrm{N}_{\mathrm{Ka}, \mathrm{Kc}}^{\mathrm{K}}\left(v_{2}\right)=7_{2,5}$. The total excitation energy of $\mathrm{E}_{\mathrm{evr}}$, which is the sum of electronic, vibrational and rotational energies, is determined to be $16,999.82 \mathrm{~cm}^{-1}$. In the same manner, many OODR spectra were measured and analyzed in the $v_{1}$-region of $16,930-16,980 \mathrm{~cm}^{-1}$. The results are listed in Table I. The bandwidth of the $v_{1}$-laser was comparable with the spin splittings. In some cases, the $F_{1}$ and $F_{2}$ levels could be assigned from the sum of $\nu_{1}$ - and $\nu_{2}$-wavenumbers. On the basis that the total angular momentum $\mathbf{J}$ must be conserved in the isolated molecule, it was possible to determine whether the intermediate rovibronic level belongs to $\mathrm{F}_{1}$ or $\mathrm{F}_{2}$. One can recognize many levels of $\mathrm{N}^{\prime}\left(v_{2}\right)$ different from $\mathrm{N}^{\prime}\left(v_{2}\right)$, which indicates that the intermediate levels are generated from at least two vibronic states through some coupling forces.

\section{DISCUSSION}

\subsection{Detection of mixed states in the $590.1 \mathrm{~nm}$ region}

Among thirty nine intermediate levels listed in Table I, twenty four levels have the quantum numbers of $\mathrm{N}^{\prime}\left(v_{2}\right)$ identical with those of $\mathrm{N}^{\prime}\left(v_{1}\right)$, while fifteen levels have the $\mathrm{N}^{\prime}\left(v_{2}\right)$ numbers different from $\mathrm{N}^{\prime}\left(v_{1}\right)$. All the thirty nine rovibronic levels have 
Table I OODR transitions and assignments measured in the $590.1 \mathrm{~nm}$ region

\begin{tabular}{|c|c|c|c|c|c|}
\hline$E_{\mathrm{evr}}\left(\mathrm{cm}^{-1}\right)$ & Assignment & $v_{1}\left(\mathrm{~cm}^{-1}\right)$ & $N_{\mathrm{Ka}, \mathrm{Kc}}^{\prime}\left(v_{1}\right)$ & $N_{\mathrm{Ka}, \mathrm{Kc}}^{\prime}\left(v_{2}\right)$ & $\Delta N^{\prime}$ \\
\hline 16979.89 & $\begin{array}{l}\mathrm{Q}(2) \\
\mathrm{P}(3)\end{array}$ & $\begin{array}{l}16947.28 \\
16944.64\end{array}$ & $2, \mathrm{~F}_{2}$ & $2{ }_{2,1} F_{2}$ & 0 \\
\hline 16979.97 & $\begin{array}{l}\mathrm{R}(3) \\
\mathrm{P}(5)\end{array}$ & $\begin{array}{l}16944.74 \\
16937.08\end{array}$ & $4_{2,3} \mathrm{~F}_{2}$ & $3_{2,1} F_{1}$ & -1 \\
\hline 16981.46 & $\begin{array}{l}\mathrm{R}(2) \\
\mathrm{Q}(3) \\
\mathrm{P}(4)\end{array}$ & $\begin{array}{l}16948.52 \\
16946.24 \\
16942.80\end{array}$ & $3_{2,1} F_{2}$ & $2_{2,1} F_{1}$ & -1 \\
\hline 16983.00 & $\begin{array}{l}\mathrm{R}(2) \\
\mathrm{P}(4)\end{array}$ & $\begin{array}{l}16950.09 \\
16944.21\end{array}$ & $3_{2,1} F_{1}$ & $3_{2,1} F_{1}$ & 0 \\
\hline 16984.81 & $\begin{array}{l}R(3) \\
P(5)\end{array}$ & $\begin{array}{l}16949.59 \\
16941.92\end{array}$ & $4_{2,3} F_{2}$ & $3_{2,1} F_{1}$ & -1 \\
\hline 16985.67 & $\begin{array}{l}R(2) \\
P(4)\end{array}$ & $\begin{array}{l}16952.76 \\
16946.87\end{array}$ & $3_{2,1} F_{1}$ & $4_{2,3} \mathrm{~F}_{2}$ & +1 \\
\hline 16986.31 & $\begin{array}{l}\mathrm{R}(3) \\
\mathrm{P}(5)\end{array}$ & $\begin{array}{l}16950.89 \\
16943.32\end{array}$ & $4_{2,3} F_{1}$ & $4_{2,3} F_{1}$ & 0 \\
\hline 16988.64 & $\begin{array}{l}R(4) \\
P(6)\end{array}$ & $\begin{array}{l}16949.98 \\
16940.70\end{array}$ & $5_{2,3}$ & $5_{2,3}$ & 0 \\
\hline 16988.81 & $\begin{array}{l}\mathrm{R}(5) \\
\mathrm{P}(7)\end{array}$ & $\begin{array}{l}16945.93 \\
16934.94\end{array}$ & $6_{2,5} \mathrm{~F}_{2}$ & $5_{2,3} F_{1}$ & -1 \\
\hline 16989.69 & $\begin{array}{l}R(3) \\
P(5)\end{array}$ & $\begin{array}{l}16954.25 \\
16946.70\end{array}$ & $4_{2,3} F_{1}$ & $5_{2,3} \mathrm{~F}_{2}$ & +1 \\
\hline 16989.70 & $\begin{array}{l}R(4) \\
P(6)\end{array}$ & $\begin{array}{l}16951.06 \\
16941.74\end{array}$ & $5_{2,3} F_{2}$ & $5_{2,3} F_{2}$ & 0 \\
\hline 16990.85 & $\begin{array}{l}\mathrm{R}(4) \\
\mathrm{P}(6)\end{array}$ & $\begin{array}{l}16952.06 \\
16942.80\end{array}$ & $5_{2,3} F_{1}$ & $5_{2,3} F_{1}$ & 0 \\
\hline 16993.94 & $\begin{array}{l}\mathrm{R}(5) \\
\mathrm{P}(7)\end{array}$ & $\begin{array}{l}16951.09 \\
16940.05\end{array}$ & $6_{2,5} \mathrm{~F}_{2}$ & $6_{2,5} \mathrm{~F}_{2}$ & 0 \\
\hline 16994.21 & $\begin{array}{l}\mathrm{R}(6) \\
\mathrm{P}(8)\end{array}$ & $\begin{array}{l}16946.25 \\
16933.56\end{array}$ & $7_{2,5} \mathrm{~F}_{2}$ & $6{ }_{2,5} F_{1}$ & -1 \\
\hline 16994.42 & $\begin{array}{l}\mathrm{R}(4) \\
\mathrm{P}(6)\end{array}$ & $\begin{array}{l}16955.65 \\
16946.35\end{array}$ & $5_{2,3} F_{1}$ & $6_{2,5} F_{2}$ & +1 \\
\hline 16995.04 & $\begin{array}{l}R(5) \\
P(7)\end{array}$ & $\begin{array}{l}16952.06 \\
16941.08\end{array}$ & $6_{2,5} \mathrm{~F}_{1}$ & $6_{2,5} \mathrm{~F}_{1}$ & 0 \\
\hline 16995.85 & $\begin{array}{l}\mathrm{R}(5) \\
\mathrm{P}(7)\end{array}$ & $\begin{array}{l}16952.85 \\
16941.91\end{array}$ & $6_{2,5} F_{1}$ & $6_{2,5} \mathrm{~F}_{1}$ & 0 \\
\hline 16999.53 & $\begin{array}{l}\mathrm{R}(6) \\
\mathrm{P}(8)\end{array}$ & $\begin{array}{l}16951.57 \\
16938.89\end{array}$ & $7_{2,5} \mathrm{~F}_{2}$ & $7_{2,5} \mathrm{~F}_{2}$ & 0 \\
\hline 16999.82 & $\begin{array}{l}\mathrm{R}(6) \\
\mathrm{P}(8)\end{array}$ & $\begin{array}{l}16951.78 \\
16939.09\end{array}$ & $7_{2,5} \mathrm{~F}_{1}$ & $7_{2,5} \mathrm{~F}_{1}$ & 0 \\
\hline
\end{tabular}


Table I (cont'd)

\begin{tabular}{|c|c|c|c|c|c|}
\hline$E_{\mathrm{evr}}\left(\mathrm{cm}^{-1}\right)$ & Assignment & $v_{1}\left(\mathrm{~cm}^{-1}\right)$ & $N_{\mathrm{Ka}, \mathrm{Kc}}^{\prime}\left(v_{1}\right)$ & $N_{\mathrm{Ka}, \mathrm{Kc}}^{\prime}\left(v_{2}\right)$ & $\Delta N^{\prime}$ \\
\hline 17000.11 & $\begin{array}{l}\mathrm{R}(7) \\
\mathrm{P}(9)\end{array}$ & $\begin{array}{l}16946.26 \\
16931.85\end{array}$ & $8_{2,7} F_{2}$ & $7_{2,5} F_{1}$ & -1 \\
\hline 17001.22 & $\begin{array}{l}\mathrm{R}(6) \\
\mathrm{P}(8)\end{array}$ & $\begin{array}{l}16953.18 \\
16940.55\end{array}$ & 7,5 & $7_{2,5}$ & 0 \\
\hline 17001.98 & $\begin{array}{l}\mathrm{R}(6) \\
\mathrm{P}(8)\end{array}$ & $\begin{array}{l}16954.03 \\
16941.31\end{array}$ & $7_{2,5} \mathrm{~F}_{2}$ & $7_{2,5} \mathrm{~F}_{2}$ & 0 \\
\hline 17002.45 & $\begin{array}{l}\mathrm{R}(7) \\
\mathrm{P}(9)\end{array}$ & $\begin{array}{l}16948.58 \\
16934.21\end{array}$ & $8_{2,7} F_{2}$ & $7_{2,5} \mathrm{~F}_{1}$ & -1 \\
\hline 17007.35 & $\begin{array}{l}\mathrm{R}(8) \\
\mathrm{P}(10)\end{array}$ & $\begin{array}{l}16946.70 \\
16930.64\end{array}$ & $9_{2,7} F_{2}$ & $8_{2,7} F_{1}$ & -1 \\
\hline 17007.46 & $\begin{array}{l}\mathrm{R}(7) \\
\mathrm{P}(9)\end{array}$ & $\begin{array}{l}16953.56 \\
16939.24\end{array}$ & $8_{2,7}$ & $8_{2,7}$ & 0 \\
\hline 17007.72 & $\begin{array}{l}\mathrm{R}(7) \\
\mathrm{P}(9)\end{array}$ & $\begin{array}{l}16953.78 \\
16939.41\end{array}$ & $8_{2,7} F_{1}$ & $9_{2,7} F_{2}$ & +1 \\
\hline 17008.90 & $\begin{array}{l}R(7) \\
P(9)\end{array}$ & $\begin{array}{l}16954.95 \\
16940.61\end{array}$ & $8_{2,7}$ & $8_{2,7}$ & 0 \\
\hline 17014.32 & $\begin{array}{l}\mathrm{R}(8) \\
\mathrm{P}(10)\end{array}$ & $\begin{array}{l}16953.66 \\
16937.62\end{array}$ & $9_{2,7}$ & $9_{2,7}$ & 0 \\
\hline 17014.90 & $\begin{array}{l}\mathrm{R}(8) \\
\mathrm{P}(10)\end{array}$ & $\begin{array}{l}16954.19 \\
16938.14\end{array}$ & $9_{2,7}$ & $9_{2,7}$ & 0 \\
\hline 17023.49 & $\begin{array}{l}\mathrm{R}(9) \\
\mathrm{P}(11)\end{array}$ & $\begin{array}{l}16955.25 \\
16937.52\end{array}$ & $10_{2,9}$ & $10_{2,9}$ & 0 \\
\hline 17024.36 & $\begin{array}{l}\mathrm{R}(9) \\
\mathrm{P}(11)\end{array}$ & $\begin{array}{l}16956.14 \\
16938.36\end{array}$ & $10_{2,9}$ & $10_{2,9}$ & 0 \\
\hline 17032.09 & $\begin{array}{l}\mathrm{R}(10) \\
\mathrm{P}(12)\end{array}$ & $\begin{array}{l}16955.38 \\
16935.94\end{array}$ & $11_{2,9}$ & $11_{2,9}$ & 0 \\
\hline 17033.68 & $\begin{array}{l}\mathrm{R}(10) \\
\mathrm{P}(12)\end{array}$ & $\begin{array}{l}16956.98 \\
16937.51\end{array}$ & $11_{2,9} F_{2}$ & $10_{2,9} F_{1}$ & -1 \\
\hline 17066.36 & $\begin{array}{l}\mathrm{R}(13) \\
\mathrm{P}(15)\end{array}$ & $\begin{array}{l}16959.29 \\
16934.79\end{array}$ & $14_{2,13}$ & $14_{2,13}$ & 0 \\
\hline 17066.86 & $\begin{array}{l}\mathrm{R}(13) \\
\mathrm{P}(15)\end{array}$ & $\begin{array}{l}16959.73 \\
16935.33\end{array}$ & $14_{2,13}$ & $14_{2,13}$ & 0 \\
\hline 17068.15 & $\begin{array}{l}\mathrm{R}(12) \\
\mathrm{Q}(13) \\
\mathrm{P}(14)\end{array}$ & $\begin{array}{l}16971.95 \\
16961.06 \\
16949.14\end{array}$ & $13_{2,11} F_{1}$ & $14_{2,13} \mathrm{~F}_{2}$ & +1 \\
\hline 17094.69 & $\begin{array}{l}\mathrm{R}(15) \\
\mathrm{P}(17)\end{array}$ & $\begin{array}{l}16963.14 \\
16935.30\end{array}$ & $16_{2,15}$ & $16_{2,15}$ & 0 \\
\hline 17104.40 & $\begin{array}{l}\mathrm{R}(16) \\
\mathrm{P}(18)\end{array}$ & $\begin{array}{l}16959.19 \\
16929.56\end{array}$ & $17_{2,15}$ & $17_{2,15}$ & 0 \\
\hline 17124.05 & $\begin{array}{l}\mathrm{R}(16) \\
\mathrm{P}(18)\end{array}$ & $\begin{array}{l}16978.82 \\
16949.21\end{array}$ & $17_{2,15} \mathrm{~F}_{1}$ & $18_{2,17} F_{2}$ & +1 \\
\hline
\end{tabular}


an identical $\mathrm{K}_{\mathrm{a}}$ number; $\mathrm{K}_{\mathrm{a}}^{\prime}\left(v_{1}\right)=\mathrm{K}_{\mathrm{a}}^{\prime}\left(v_{2}\right)=2$. There are three types of the relations between $\mathrm{N}^{\prime}\left(v_{1}\right)$ and $\mathrm{N}^{\prime}\left(v_{2}\right): \Delta \mathrm{N}^{\prime}=\mathrm{N}^{\prime}\left(v_{2}\right)-\mathrm{N}^{\prime}\left(v_{1}\right)=0$ and \pm 1 . Figures 2 and 3 plot the energies of all the intermediate levels listed in Table I against the rotational quantum numbers $\mathrm{N}^{\prime}\left(v_{2}\right)$ and $\mathrm{N}^{\prime}\left(v_{1}\right)$, respectively. If $\mathrm{NO}_{2}$ is a regular molecule, the reduced level energies, $E_{\text {red }}=E_{\text {evr }}-0.3 \mathrm{~N}^{\prime}\left(\mathrm{N}^{\prime}+1\right)$, should have a linear correlation vs. $\mathrm{N}^{\prime}\left(\mathrm{N}^{\prime}+1\right)$.



Figure 2 Plot of the reduced rovibronic energies, $\mathrm{E}_{\text {red }}=\mathrm{E}_{\text {evr }}-0.3 \mathrm{~N}^{\prime}\left(\mathrm{N}^{\prime}+1\right)$, against $\mathrm{N}^{\prime}\left(\mathrm{N}^{\prime}+1\right)$. Here, $\mathrm{N}^{\prime}$ denotes $\mathrm{N}^{\prime}\left(v_{2}\right)$. Fitting of the data to the equation, $\mathrm{E}_{\mathrm{evr}}=\mathrm{T}_{\mathrm{v}}+(\mathrm{A}-\overline{\mathrm{B}}) \mathrm{K}_{\mathrm{a}}^{2}+\overline{\mathrm{B}} \mathrm{N}(\mathrm{N}+1)$, gives the molecular constants; $T_{v} \sim 16,947 \mathrm{~cm}^{-1}$ and $\bar{B} \sim 0.43 \mathrm{~cm}^{-1}$ assuming that $(\mathrm{A}-\overline{\mathrm{B}})=7.5 \mathrm{~cm}^{-1}$.

Roughly speaking, the $\mathrm{E}_{\text {evr }}$ vs. $\mathrm{N}^{\prime}\left(v_{2}\right)$ plot exhibits a linear relation as shown in Figure 2. Many levels with the same $\mathrm{N}^{\prime}$ and $\mathrm{K}_{\mathrm{a}}^{\prime}$ quantum number exist in the energy region spread over a few wavenumbers. There exist six levels with an identical rotational quantum number of $\mathrm{N}^{\prime}\left(v_{2}\right)=7$. Five levels exist as $\mathrm{N}^{\prime}\left(v_{2}\right)=5$ or 6 , and 
three levels as $\mathrm{N}^{\prime}\left(v_{2}\right)=3,8,9$, or 10 . The maximum number of levels with an identical rotational $\mathrm{N}^{\prime}$ and $\mathrm{K}^{\prime}$ quantum number was six in the $590.1 \mathrm{~nm}$ region. If $\mathrm{NO}_{2}$ is a regular molecule, the level number of identical $\mathrm{N}$ and $\mathrm{K}_{\mathrm{a}}$ numbers is expected to be two at the most due to the spin splitting. The state mixing must be necessarily considered to account for abnormal level numbers measured.

Figure 3 plots the reduced level energies against $\mathrm{N}^{\prime}\left(v_{1}\right)$. The linearity is not apparent in Figure 3 any more. However, one can recognize that each of three groups of $\Delta \mathrm{N}^{\prime}=0, \pm 1$ consists of one series, which suggests that three vibronic states may contribute to the $v_{1}$-transition from the ground state.

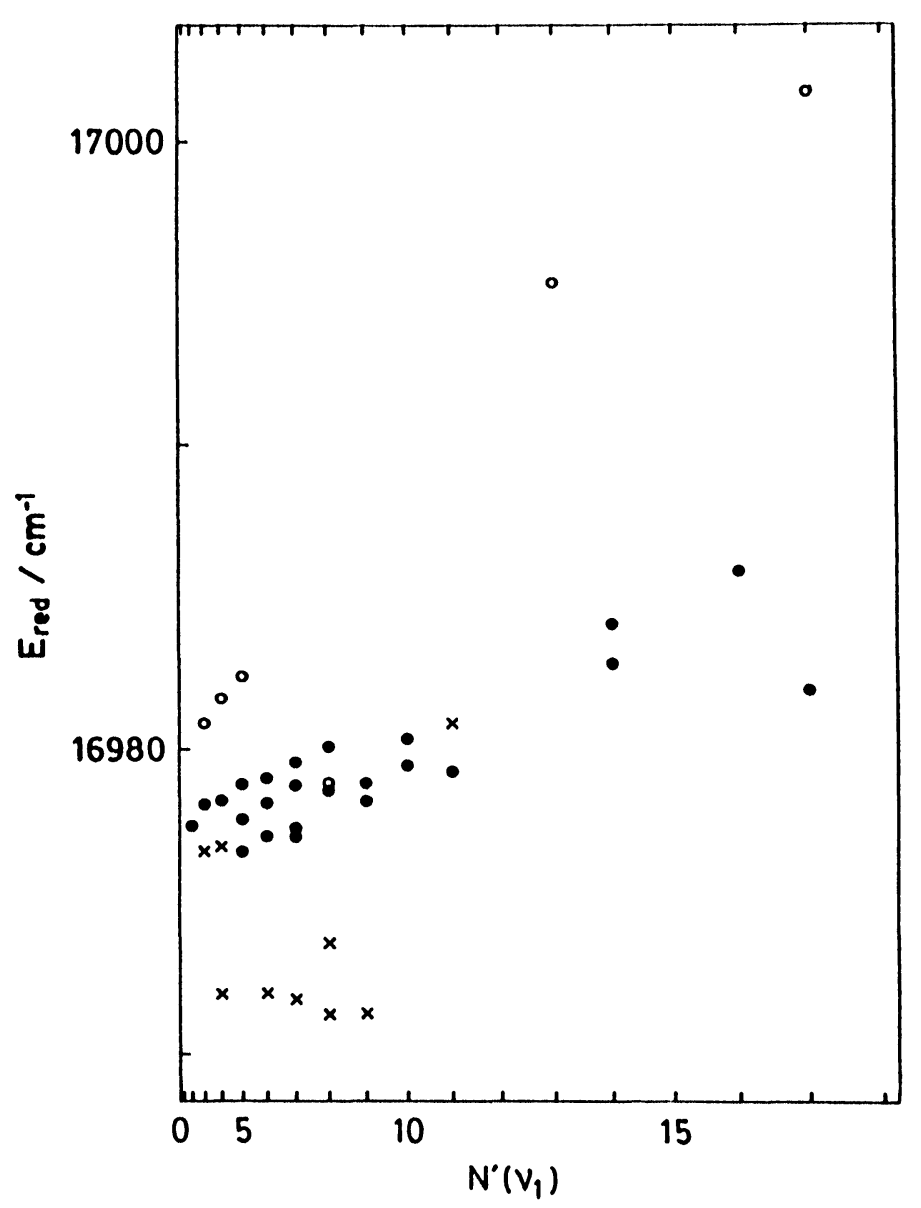

Figure 3 Plot of the reduced rovibronic energies, $E_{\text {red }}=E_{\text {evr }}-0.4 N^{\prime}\left(N^{\prime}+1\right)$, against $N^{\prime}\left(N^{\prime}+1\right)$. Here, $\mathrm{N}^{\prime}$ denotes $\mathrm{N}^{\prime}\left(v_{1}\right)$. Three groups of levels may be recognized depending on the interaction selection rules: $\Delta \mathrm{N}^{\prime}=\mathrm{N}^{\prime}\left(v_{2}\right)-\mathrm{N}^{\prime}\left(v_{1}\right)=+1$ (open circle), 0 (closed circle), and -1 (cross). Fitting of the closed circle data to the equation, $E_{\text {evr }}=T_{v}+(A-\bar{B}) K_{a}^{2}+\bar{B} N(N+1)$, gives the molecular constants; $T_{v}$ $16,947 \mathrm{~cm}^{-1}$ and $\overline{\mathrm{B}} \sim 0.41 \mathrm{~cm}^{-1}$ assuming that $(\mathrm{A}-\overline{\mathrm{B}})=7.5 \mathrm{~cm}^{-1}$. 
We could not detect a $K_{a}^{\prime}=0$ or 1 stack in this OODR experiment, and therefore we can not determine the exact $T_{v}$ value of this vibronic level. The band origin $\left(T_{v}\right)$ was estimated to be around $16,947 \mathrm{~cm}^{-1}$ from the analysis the $\mathrm{K}_{\mathrm{a}}^{\prime}=2$ data in Figures 2 and 3 under the assumption that $(A-\bar{B})=7.5 \mathrm{~cm}^{-1}$. The question here is which zeroth-order vibronic states among $A_{1}, A_{2}$ and $B_{1}$, and $B_{2}$ make the mixed state in this energy region and are detected by the present OODR method.

\subsection{State interaction mechanism and OODR spectroscopy}

The main experimental features of the mixed state observed in the $590.1 \mathrm{~nm}$ region and the assignments of composite zeroth-order states are summarized as follows.

(I) All the $v_{1}$-transitions originating with $\widetilde{X}^{2} \mathrm{~A}_{1}(0,0,0)$ are of a parallel type and therefore the composite state of the mixed state responsible for the $v_{1}$-transition is conclusively ${ }^{2} \mathrm{~B}_{2}$.

(II) From the $v_{1}$-transition in OODR, one can classify thirty nine rovibronic levels belonging to the mixed state into three zeroth-order vibronic levels as seen in Figure 3. Three research groups have carried out the jet-cooled LIF experiments in this energy region $2,4,5$ and found a strong vibronic band at $16,946.711 \mathrm{~cm}^{-1}$. We can not compare our $\mathrm{K}_{\mathrm{a}}^{\prime}=2$ data directly with their jet-cooled LIF data, because the jet-cooled experiments provide only the information on the lowest $\mathrm{N}$ levels in the $\mathrm{K}_{\mathrm{a}}=0$ stack. The $T_{v}$ value of the vibronic state, to which the $K_{a}^{\prime}=2$ levels detected by OODR belong, is estimated to around $16,947 \mathrm{~cm}^{-1}$, which accords with the band origin of $16,946.711 \mathrm{~cm}^{-1}$ measured in the supersonic jet. Thus, we conclude that at least one of the composite states responsible for the $v_{1}$-transition is the ${ }^{2} \mathrm{~B}_{2}$ vibronic state which has the band origin at $16,946.711 \mathrm{~cm}^{-1}$.

(III) All the $v_{2}$-transitions terminating on $2^{2} \mathrm{~B}_{2}$ are of a perpendicular type and therefore the composite state of the mixed state responsible for the $v_{2}$-transition is ${ }^{2} \mathrm{~B}_{2}$ or $\widetilde{C}^{2} \mathrm{~A}_{2}$. If the levels of $\mathrm{K}_{\mathrm{a}}^{\prime}=0$ or 1 are detected, then we could determine whether the vibronic state responsible for the $v_{2}$-transition is $\mathrm{B}_{2}$ or $\mathrm{A}_{2}{ }^{11-13}$ For the intermediate state studied in this experiment, we could detect only the $\mathrm{K}_{\mathrm{a}}^{\prime}=2$ levels and it is rather difficult to determine the vibronic symmetry from the rotational structure. The clue may exist in the value of the band origin, $T_{v} \sim 16,947 \mathrm{~cm}^{-1}$. We have already reported the $T_{v}$ values of $\widetilde{C}^{2} A_{2}$ to be $16,970 \mathrm{~cm}^{-1}$ for $(0,1,0),{ }_{1}^{11}$ and $17,710 \mathrm{~cm}^{-1}$ for $(0,2,0)$ or $(1,0,0) .^{13}$ The vibronic level detected in this study lies about $20 \mathrm{~cm}^{-1}$ below $\widetilde{\mathrm{C}}^{2} \mathrm{~A}_{2}(0,1,0)$ and $690 \mathrm{~cm}^{-1}$ above $\widetilde{C}^{2} \mathrm{~A}_{2}(0,0,0){ }^{16}$ It is likely that the vibronic state $\left(T_{v} \sim 16,947 \mathrm{~cm}^{-1}\right)$ responsible for the $v_{2}$-transition is not $A_{2}$ but $B_{2}$. It might be worthy of note here that the $B_{2}$ vibronic levels are much dense (one level every $10 \mathrm{~cm}^{-1}$ ) than the $A_{2}$ levels (one level every $500 \mathrm{~cm}^{-1}$ ) in this energy region. Thus, a mixed state detected in the $590.1 \mathrm{~nm}$ region is concluded to be composed of two ev $B_{2}$ states: One $\left(B_{2}^{\prime \prime}\right.$ state) and another $\left(\mathrm{B}_{2}^{\prime}\right)$ states are responsible for the $v_{1}$ - and $v_{2}$-transitions, respectively.

(IV) The selection rules between $\mathrm{N}_{\mathrm{Ka}, \mathrm{Kc}}^{\prime}\left(\nu_{1}\right)$ and $\mathrm{N}_{\mathrm{Ka}, \mathrm{Kc}}^{\prime}\left(\nu_{2}\right)$ are expressed as $\Delta \mathrm{N}^{\prime}$ $=0, \pm 1$, and $\Delta \mathrm{K}_{\mathrm{a}}^{\prime}=0$, which implies that the spin-orbit interaction contributes at 
least partly to generation of the mixed state. Furthermore in some of $v_{2}$-scanned spectra, we observed abnormally weak ${ }^{\mathrm{P} Q}$ branches (for example ${ }^{\mathrm{P}} \mathrm{Q}_{2}(14)$ ), which suggest that an $\mathrm{A}_{1}$ vibronic state (one level every $10 \mathrm{~cm}^{-1}$ ) is also included in the mixed state. The similar spin-orbit (and/or orbital-rotation) coupling between $\mathrm{B}_{2}$ and $\mathrm{A}_{1}$ vibronic levels is also recognized in the region of $612-614 \mathrm{~nm} .{ }^{10}$

(V) Many levels of identical $\mathrm{N}_{\mathrm{Ka}, \mathrm{Kc}}^{\prime}\left(v_{2}\right)$ quantum numbers were detected in a narrow energy region of a few wavenumbers. For example, six levels were detected as $7_{2,5}\left(v_{2}\right)$ in the $\mathrm{E}_{\text {evr }}$ region of $16,999.53-17,002.45 \mathrm{~cm}^{-1}$ (Table I). These levels of an identical rotational quantum number scatter over $3 \mathrm{~cm}^{-1}$ but may be recognized as a $\mathrm{K}_{\mathrm{a}}^{\prime}=2$ stack of one severely-perturbed vibronic state as a whole. Due to the nuclear spin $(\mathrm{I}=1), \mathrm{NO}_{2}$ has six spin sublevels, but the hyperfine splitting is much smaller than spectral resolution of lasers employed. This particular six-level interaction case can be rationalized by a coupling scheme illustrated in Figure 4. Two composite $B_{2}$ vibronic levels are required to make the mixed state. They are denoted as $B_{2}^{\prime}$ and $\mathrm{B}_{2}^{\prime \prime}$, which are responsible for the $v_{2}$ and $v_{1}$-transitions, respectively. The spin-orbit and orbital-rotation interactions can not mix the vibronic state with identical symmetry $\left(B_{2}-B_{2}\right.$ interaction). Therefore, the $A_{1}$ vibronic state must be considered into the coupling scheme between $B_{2}^{\prime}$ and $B_{2}^{\prime \prime}$. This indirect coupling via $A_{1}$ vibronic states accounts for the level number of $7_{2,5}\left(\nu_{2}\right)$. The spin-orbit interaction combines $B_{2}$ and $\mathrm{A}_{1}$ vibronic states with the selection rules that $\Delta \mathrm{N}=0, \pm 1$ and $\Delta \mathrm{K}_{\mathrm{a}}= \pm 1$. The orbital-rotation interaction mixes $B_{2}$ and $A_{1}$ vibronic states under the selection rules

\section{ZEROTH-ORDER STATES}

MIXED STATES

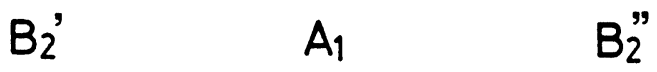

$\mathrm{J}, \mathrm{N}, \mathrm{Ka}$
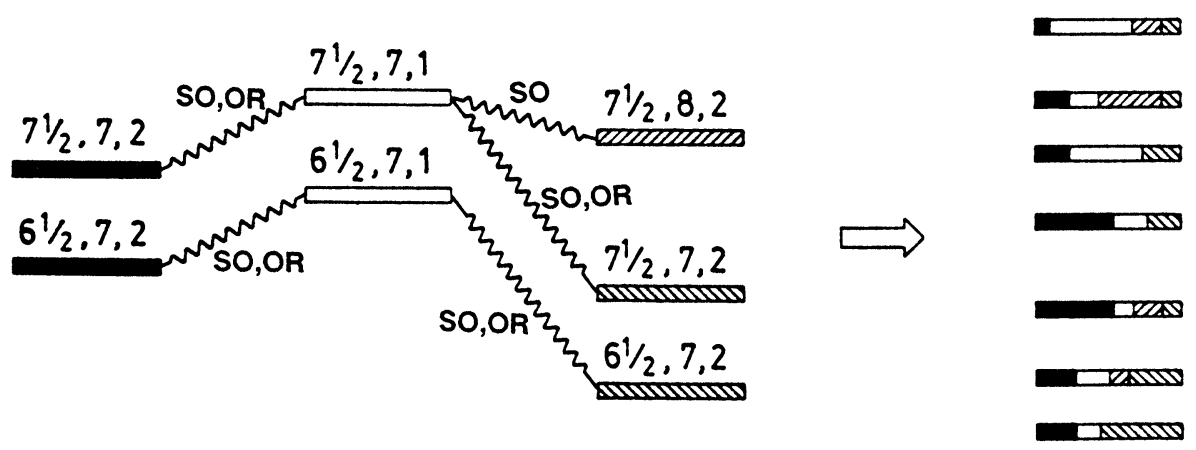

Figure 4 Multi-state coupling scheme for $7_{2,5}\left(v_{2}\right)$ levels. The quantum numbers of $J, N$, and $K_{a}$ are indicated for the zeroth-order rovibronic levels. The $\mathrm{B}_{2}^{\prime}, \mathrm{A}_{1}$, and $\mathrm{B}_{2}^{\prime \prime}$ zeroth-order states are shown in the first (filled square levels), second (open square levels), and third (hatched square levels) columns, respectively. Symbols of SO and OR denote spin-orbit and orbital-rotation interactions, respectively. The mixed states are schematically presented in the fourth column. See the text in detail. 
that $\Delta \mathrm{N}=0$ and $\Delta \mathrm{K}_{\mathrm{a}}= \pm 1$. Hence the $\mathrm{A}_{1}$ vibronic state with $\mathrm{K}_{\mathrm{a}}=1$ or 3 can interact with the $\mathrm{B}_{2}$ vibronic state with $\mathrm{K}_{\mathrm{a}}=2$. The experimental results obtained by this OODR study can be reasonably explained by the model described in Figure 4, where the $K_{a}$ value of the $A_{1}$ vibronic state is assumed to be 1 .

The complexity of the visible spectrum of $\mathrm{NO}_{2}$ is caused primarily by the strong vibronic interaction between $\widetilde{B}^{2} B_{2}$ and $\widetilde{X}^{2} A_{1}$ states. In addition to vibronic interaction, the spin-orbit and orbital-rotation interactions must be considered to elucidate the interaction network of excited $\mathrm{NO}_{2}$. In this OODR study we present the experimental evidence to show that $A_{1}$ vibronic levels play an important role to perturb the $B_{2}$ vibronic levels.

\section{Acknowledgments}

The authors are grateful to Professor Kinichi Obi (Tokyo Institute of Technology) for his encouragement throughout of this work and Professor Kentaro Kawaguchi (Nobeyama National Observatory) for his help on the energy calculation.

\section{References}

1. D. K. Hsu, D. L. Monts and R. N. Zare. "Spectral Atlas of Nitrogen Dioxide 5530 to $6480 \AA$ ", (Academic, New York, 1978); K. Uehara and H. Sasada, "High Resolution Spectral Atlas of Nitrogen Dioxide 559-597 nm"' (Springer, Heidelberg, 1985).

2. R. E. Smalley, L. Wharton and D. H. Levy. J. Chem. Phys., 63, 4977 (1975).

3. S. Hiraoka, K. Shibuya and K. Obi. J. Mol. Spectrosc., 129, 427 (1987).

4. G. Persch, E. Mehdizadeh, W. Demtröder, Th. Zimmermann, H. Köppel and L. S. Cederbaum. Ber. Bunsenges. Phys. Chem., 92, 312 (1988).

5. A. Delon, R. Jost and M. Lambardi. J. Chem. Phys., 95, 5701 (1991).

6. M. Baba, H. Yamada and K. Nishizawa. J. Chem. Phys., 97, 4569 (1992).

7. J. C. D. Brand and P. H. Chiu. J. Mol. Spectrosc., 75, 1 (1979).

8. K. Tsukiyama, K. Shibuya, K. Obi and I. Tanaka. J. Chem. Phys., 82, 1147 (1985).

9. K. Shibuya, T. Kusumoto, H. Nagai and K. Obi. Chem. Phys. Letters, 152, 129 (1988).

10. H. Nagai, K. Shibuya and K. Obi. J. Chem. Phys., 93, 7656 (1990).

11. H. Nagai, K. Aoki, T. Kusumoto, K. Shibuya and K. Obi. J. Phys. Chem., 95, 2718 (1991).

12. K. Shibuya, T. Kusumoto, H. Nagai and K. Obi. J. Chem. Phys., 95, 720 (1991).

13. K. Aoki, H. Nagai, K. Hoshina and K. Shibuya. J. Phys. Chem., (in press)

14. W. C. Bowman and F. C. De Lucia. J. Chem. Phys., 77, 92 (1982).

15. K.-E. J. Hallin and A. J. Merer. Can. J. Phys., 54, 1157 (1976).

16 A. Weaver, R. B. Metz, S. E. Bradforth and D. M. Neumark. J. Chem. Phys., 90, 2070 (1990). 